\title{
Preface of the CSR Supplement Issue: Proceedings of the 9th International Conference on Nearshore and Estuarine Cohesive Sediment Transport Processes
}

\author{
${ }^{a}$ Department of Coastal Environment Dynamics, IFREMER, France \\ ${ }^{\mathrm{b}}$ Department of Civil Engineering, Katholieke Universiteit Leuven, Belgium \\ ${ }^{\mathrm{c}}$ Department of Coastal Environment Dynamics, IFREMER, France \\ * Corresponding author : P. Le Hir, email address : Pierre.Le.Hir@ifremer.fr
}

Intercoh is a regular international conference focused on cohesive sediment transport in rivers, lakes, reservoirs, estuaries, coastal areas and on the continental shelf.

Cohesive sediments often play a key role within the ecosystem. For instance, high suspended sediment concentrations limit primary production through light attenuation in the water column, while the nature of sedimentary deposits widely controls habitats of benthic communities. Fine sediments also tend to accumulate in still water areas, such as harbour basins and navigation channels, which leads to costly dredging activities. Because of their chemical properties, cohesive particles tend to attract contaminants, thereby making such particles contaminant carriers.

The Intercoh conference series, initiated by Prof. A.J. Mehta, is an international platform where scientists and engineers worldwide can meet and exchange experiences to develop a better understanding of the transport of fine-grained sediments. The 9th edition was held in Brest (France), on September 25-28, 2007. Previous editions took place in Florida (USA), in Wallingford (UK, 1994), in Seoul (Korea, 1998), in Delft (The Netherlands, 2000), in Virginia (USA, 2003) and in Saga (Japan, 2005). About one hundred scientists attended the Intercoh'07 issue.

The Intercoh'07 conference was dedicated to Claude Migniot, who initiated pioneering research on cohesive sediments in France, in the 1960s. Holding a Ph.D. in sedimentology, Claude Migniot was the head of the Sedimentology Department in a major hydraulic laboratory (Laboratoire Central d'Hydraulique de France) before working as an expert for Sogreah (Grenoble). He taught sediment dynamics in several universities and engineering schools. The essentials of his work are reported within two main publications in the French scientific journal "La Houille Blanche" ([Migniot, 1968], [Migniot, 1989a] and [Migniot, 1989b]). His main contributions are related to settling and flocculation, consolidation, rheology and erosion processes, but he also dealt with underwater equilibrium slopes of muddy sediment, turbidity currents, similitude problems in scale models and sand behaviour under wave action. He also lead many engineering studies either in sandy coasts (beach nourishment, sand extraction and coastal defence), in muddy areas (geomorphology of the Gironde and Loire estuaries) or in mixed environments (Mont St-Michel Bay, Marennes-Oléron Bay, etc). One of his merits consisted in using a similar protocol for different materials and study areas, so that he was able to compare sediment behaviours and to identify general trends and laws, using both field measurements and laboratory experiments. For instance, he proposed a unique relationship between the critical shear stress for erosion and the vane shear strength, while the latter can be related to the dry concentration for a given type of mud. He described the influence of sand on this erosion shear 
strength, and initiated experimental works on mixed sediments. He built up a considerable database of consolidation curves from settling column experiments, noticing the increase of the vertical gradient of concentration and the increase of consolidation rate with the individual particle size. Last, he measured the distribution of settling velocities for natural mud from many locations all over the world, either flocculated or not. He obtained a much narrower spectrum of settling velocities when cohesive material is flocculated, and introduced a flocculation factor as a ratio between flocculated and unflocculated sediments. A major outcome is a strong dependence of this flocculation factor on the particle diameter. Claude Migniot tackled nearly all aspects of cohesive sediment dynamics, and brought many original insights that are still up to date. The Cohesive Sediment scientific community is indebted to Claude Migniot's findings and intuition: this is why we dedicated the Intercoh'07 conference to him.

This special issue displays a panel of papers that reveal the relevant research axes related to cohesive sediment transport today:

(i) The first two papers are related to the erodibility of sediments constituted of sand/mud mixtures (Dickudth et al. and Jacobs et al.), while the third paper deals with the possibility to use remote sensing to characterize natural sediment behaviours on mudflats, in relation with microphytobenthos (Adam et al.).

(ii) A second group of 5 papers deals with suspensions and flocculation processes. Sottolichio et al., compare sediment fluxes with or without turbulent mixing in highly turbid environments, and Smith et al. illustrate the settling characteristics of dredged sediments. The three following papers present new techniques of flocculation modelling (Verney et al., Maerz et al. and Zhang et al.).

(iii) The evolution of deposited material is considered in a third group of two papers: Camenen et al. investigate sedimentation and early consolidation of highly concentrated sediment suspension while Thiébot et al. propose a simple method to assess the parameterization of consolidation models from settling column experiments.

(iv) Two papers are specifically dedicated to the modelling of mixed sediment transport (Van Kessel et al. and Le Hir et al.)

(v) A group of three papers is dedicated to the Scheldt estuary, either through the analysis of suspended material observed in the field (Manning et al.) or the use of numerical models (van Kessel et al. and van Maren et al.).

(vi) The last paper is related to long term morphological modelling, adapted to the case of cohesive sediments in intertidal areas (Spearman).

Recurrent topics of cohesive sediment dynamics dominated the sessions of the conference, among them consolidation and erodibility processes, and especially flocculation processes that were the focus of the three sessions (laboratory and field studies, modelling approaches). But the conference was also marked by rising topics such as the behaviour of sand/mud mixtures and the interactions between sediment and biota, leading to the emerging discipline of ecogeomorphology. 


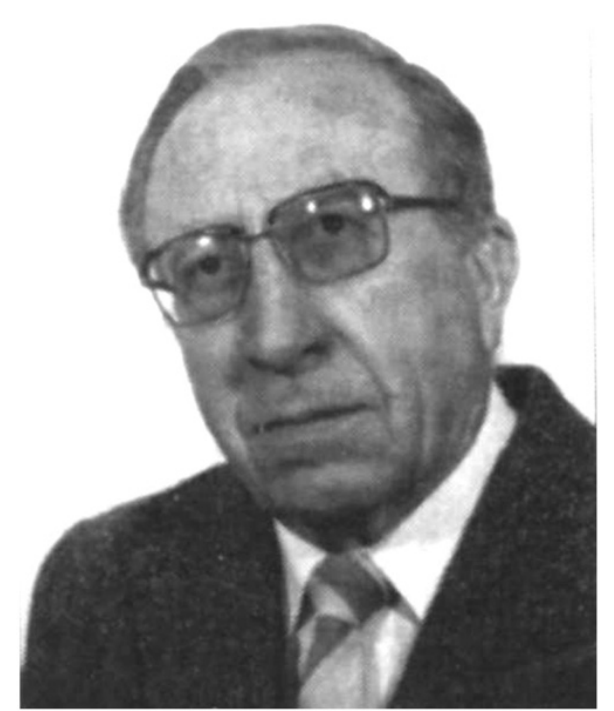

Claude Migniot

\section{Acknowledgement}

The organisers of the conference and the guest editors are most grateful to the French Institute for the Exploitation of the Sea (IFREMER), the Research Institute for Development (IRD), the Brittany council (Région Bretagne), the Conseil Général du Finistère/Penn-ar-Bed, the city of Brest and nke instrumentation company for their financial support for the conference and the proceedings publication.

\section{References}

Migniot, 1968 C. Migniot, Etude des propriétés physiques de différents sédiments très fins et de leur comportement sous les conditions hydrodynamiques, La Houille Blanche 7 (1968) (1968), pp. 591620.

Migniot, 1989a C. Migniot, Tassement et rhéologie des vases: $1^{\text {ère }}$ partie, La Houille Blanche 1 (1989), pp. 11-29.

Migniot, 1989b C. Migniot, Tassement et rhéologie des vases: $2^{\text {ème }}$ partie, La Houille Blanche 2 (1989), pp. 95-111. 